The use of narrative in preparing mental health nursing staff to undertake clinical supervision

Steve Lyon ${ }^{1}$

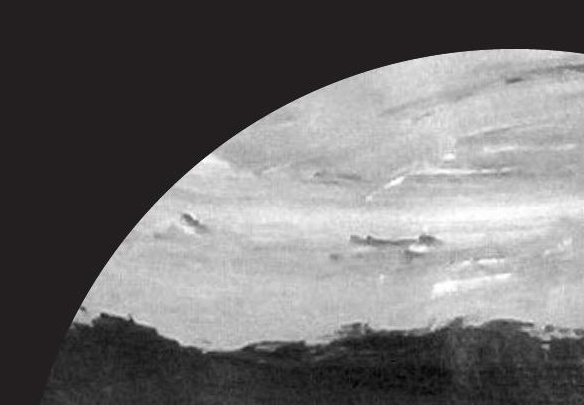

Steve Lyon

${ }^{1}$ University of Huddersfield 


\title{
The use of narrative in preparing mental health nursing staff to undertake clinical supervision
}

S R Lyon

\section{Abstract}

There is considerable interest in the use of narrative by healthcare professionals. This ranges from those who are exploring its use as a therapeutic method through to those who are interested in its use within research. This paper examines, through a personal reflective account, the use of narrative as a method of engaging participants in the learning process within a training programme* preparing mental health nursing staff to undertake clinical supervision. The paper suggests that the use of narrative is a much more powerful method of facilitating learning than the use (and in many cases over use) of technology such as PowerPoint and overhead projector. This paper argues that effective clinical supervisors assist in the 'telling of stories' and therefore it makes sense to encourage story telling and story listening within the training programme itself. Here, I also describe the facilitator** style required to encourage the sharing of narratives. This paper discusses, albeit briefly, the use of group teaching methods that foster a 'sense of community' countering a sense of isolation and disengagement which, I suggest, is very much apparent in modern day society and a symptom of burnout, and frequently observed in mental health nurses.

Keywords: Burnout, Clinical supervision, Engagement, Narrative, Training programme

*the term training programme is used interchangeably with other terms such as training course, development programme, educational programme, and training workshop.

**Although the term facilitator is the preferred term used within this paper, others such as tutor and teacher also appear. The term facilitator, to me, implies a collaborative relationship between learner and other, and suggests an active as opposed to passive learning process.

\section{Introduction: Facilitators as story tellers}

\author{
Are you sitting comfortably....
}

"The most surprising part is that I qualified as a mental health nurse in the first place. It's not every student nurse on their first placement, stumbles upon a patient hanging dead by a tie, and goes on to complete the course. The lack of support I got at the time convinced me more than anything that nurses needed a supportive process like clinical supervision".

The above paragraph is a summary of a true story narrated in much richer detail by myself, with a great degree of sensitivity. The story, and other stories like it, are told at the beginning of a programme preparing nursing staff to become either clinical supervisors or clinical supervisees. They are used as a method for 'capturing the hearts and minds' of participants, some of whom may have not had a choice but to come on the programme. Clinical supervision training borders on being a mandatory requirement in many trusts, with all the 'baggage' that creates for the unwilling 'traveller'.

Compare the telling of a good story at the start of a training event with the bland recital of a list of objectives projected onto a wall in a classroom. This practice is one frequently encouraged on 'train the teachers' courses, where they are indoctrinated in the art of always reciting the expected outcomes at the start of every session. Its very blandness is suggested by the mantra 'first tell them what you are going to tell them, tell them, and then tell them what you've told them'. This monotonous process is temporarily offset by the monotonous use of technology to keep a flicker of interest. 
Clarke (2003) describes how in nurse education there is an over reliance on 'teaching aids'. This has, according to Clarke, resulted in barriers to meaningful discussion between tutors and students, and resulted in diminished learning opportunities. It has quite strikingly been described as 'death by overhead'. Clarke appeals for a return to more traditional methods of teaching, what I would call "talk without chalk".

It is easy to appreciate the embrace of PowerPoint, by tutors, when faced with an audience fed regularly on (super) graphics, and whose palate is unaccustomed to a seemingly bland diet of reflective discussion. Here lies the challenge; to excite the participants through relevant and appropriate stories whilst avoiding the charge of over-stimulation and shallowness. Without due care, attention, and sensitivity the use of stories are mere substitutes for the technology from which we are attempting to wean them, but used appropriately, as McAllister (2001) observes, narratives have the "power to move and transform people".

Apart from its function as an initial engagement strategy, there are a number of other appropriate reasons for employing narrative on programmes preparing clinical supervisors.

\section{The place of narrative within clinical supervision}

\section{A frequently told and popular joke unfolds as follows:}

'Bill and Ted are walking down a street. Bill is accompanied by a dog, Ted asks "Does your dog bite?", to which Bill replies, "No my dog doesn't bite". Ted is most angry when attempting to pat the dog's head his hand is bitten. "I thought you said your dog doesn't bite ", to which Bill replies "He doesn't - that's not my dog".

I recall a similar tale involving an elaborately staged entrance to a group of students. The group of students are unknown to the author. The incident involved plenty of slapstick with the purpose of grabbing the group's attention but which resulted in classroom mayhem (I 'died on stage'). Once I had recovered I angrily challenged the group's 'normal' tutor: "I thought your class liked a good joke", to which the tutor replied, "My class does like a good joke - that's not my class. You were in the wrong classroom!" .

I tell this tale a lot to students when we first meet, with the intention of lightening the initial tension and establishing rapport. I learn something new every time I retell the story. Similarly, if I was reflecting and narrating this account in my own clinical supervision, I might explore the critical incident at different levels and from a number of different angles. The narrating of stories fires the fuel of clinical supervision and ultimately makes the thing work. I therefore suggest that any training intending to prepare clinical supervisors should focus on the task of storytelling.

Many books on clinical supervision emphasise the process of storytelling. For instance, Driscoll (2000) discusses the role of clinical supervisees in clinical supervision, and emphasises the need for supervisees to prepare for the process. One of the tasks of the clinical supervisee, he suggests, is to prepare a story to narrate and then tell the story. Johns (2002) also includes chapters on narrative in his book on guided reflection, and Ghaye (2000) refers to what he calls a 'clinical conversation' which takes place within clinical supervision.

Mcleod (2002) describes in detail the use of narrative as a method for learning and problem solving. For instance, he writes: "...everyone has experiences that are perplexing and somehow 'unfinished' until they can be told to someone else...". Later, in the same chapter he suggests that it is by recounting past experiences to some other that we learn to problem solve.

The example of the 'wrong class' described at the beginning of this section, provides an illustration of a 'somehow unfinished experience' which could be subjected to 'problem solving' explorations in clinical supervision. Using the 'wrong class' as a for instance, during clinical supervision, I could have been asked quite practical questions such as: 
"On reflection, what could you have done that would have prevented the mistake happening in the first place?"

"If you were in a similar situation in the future, and obtaining a poor response from the group, what would you do?".

These are two good questions that help the person reflect on past experience and consider what can be done differently in future. This of course supports models of reflective practice which describe stages in which people reflect on experiences to do things differently (or indeed same) in the future as described by Schon (1983)

The need to work with narrative as a means to develop critically thinking health professionals is currently being evaluated. For instance, Khanna (2004) identifies narrative reflection as a basic requirement on a pathway to the development of critically thinking occupational therapists.

Hopefully, these examples help emphasise the benefits of using narrative in clinical supervision, and therefore, any training programme preparing both clinical supervisors and clinical supervisees for the process of clinical supervision, must include working with narrative. Clinical supervisors, in particular, need to acquire the skills and qualities that promote storytelling in their supervisees, and supervisees need to acquire the ability and willingness to share stories.

\section{The development of effective story-listeners and story tellers}

In 2002, I was involved with a clinical nurse manager in designing and facilitating a programme to prepare nursing staff to become clinical supervisors. We had in mind the following two intentions:

1 The programme would translate into practice; it would not be one of those training events that made no difference; trained clinical supervisors would continue to provide clinical supervision beyond the life of the training course.

2 The programme would inspire; the participants would be enthusiastic about the process both during and beyond the training programme. In this way, we believed, the clinical supervisors would be committed to the process of clinical supervision.

The translation into practice was achieved by training small groups of staff, who came onto a training workshop in pairs, predominantly from the same service (type and geography). The clinical supervisee and their clinical supervisor enrolled onto the training programme and were subject to the same learning material, and were provided with practice opportunities whilst on the course.

Altogether, we ran three separate workshops. These training workshops took place over a period of on average two months, and thus allowed the supervision pairs to transfer learning into practice, and to provide feedback on progress. At a follow up date, the supervision pairs came back to share their stories.

The feedback opportunity modelled the reflective process, and further developed their understanding of reflective practice. This of course, required much sensitivity and management especially in respect of keeping the content of clinical supervision confidential.

Translation into practice was assisted by both clinical supervisors and their clinical supervisees hearing and being inspired by the same stories. Together they explored and extended the stories they had heard. Together they checked out their understandings and how these stories had affected them. Together they struggled with some of the more difficult material presented on the programme and this helped facilitate the process of joint problem solving.

This notion of training pairs who come from the same part of the service echoes some of the work on designing learning organisations. Learning organisations are those which foster a culture of inquiry and the embracing of best practice. Senge (1994), writing on building a learning organisation, emphasised facilitating team building 
resulting in shared visions and mental models, and team learning. Learning in teams, it is suggested by Nonaka and Takeuchi (1995), is critical for the engagement with 'best practice'. Currently, there is considerable interest in the process of establishing what Wenger (1998) calls communities of learning practice; groups of people working together to introduce and support best practice. This initiative was an attempt to establish a community of learning practice in order to introduce and sustain the process of clinical supervision. It was a community established through the sharing of stories. McAllister (2001) describes how the use of shared stories evokes a "collective cultural wisdom" in nursing, and it was my intention to establish a local culture with the collective wisdom to embrace and maintain clinical supervision.

There are other, perhaps more obscure, benefits in using group methods of teaching that encourage the sharing of stories. Maslach and Letter (1997) describe the causes of burnout, and in particular discuss how the modern organisation has resulted in many employees feeling isolated and disengaged. The current growth in self help and life coaching books aiming to reduce the emotional cost of burnout would testify to the increase in its prevalence. Winstanley et al (2003), Hawkins and Shohet (2000) suggest that health professionals who are particularly prone to burnout may be helped through clinical supervision. The sharing of stories may help people feel part of the culture and hence less isolated and more protected from burnout.

\section{Facilitators as story listeners}

The teaching method and style adopted by both myself and my co-facilitator were those that encouraged 'story sharing'. Thus it was a conscious decision to avoid a prescriptive inflexible timetable of events, that we'd slavishly adhered to. Rather, we took on a style advocated by Musson (1998) for story listeners; that of a flexible non directive listener who is "fluid as the situation demands........ rather than impose some rigid predetermined framework". Powerpoint presentation, with its preordained sequence of learning slides efficiently matched with desired outcomes, does not lend itself to this person centred style of facilitating.

This said, I do not want to give the impression that the essential skills, qualities and knowledge necessary for effective clinical supervision were not addressed on the Workshop. Indeed, underpinning the course was a framework of competencies associated with effective clinical supervision which was used as a baseline benchmark, and as a tool to assist focused reflective practice and assessment. Still, I wish to emphasise the oral/aural methods of teaching method used to facilitate the acquisition of skills and knowledge that underpin a mainly oral/aural process.

Tutor, teacher, facilitator, lecturer; these titles are enough to turn people into quivering wrecks. The real tragedy is that the encounter between learner and teacher should be one of those transformational moments where the possibilities of real growth are possible. Put aside, for the moment, the 'tall poppies' (those obvious future leaders who stand head and neck above the rest) they will find their own growing opportunities; instead focus on nurturing the 'shrinking violets'. These are the majority, and the ones in need of fertile experiences. If only they weren't so afraid of the gardeners! The growing amount of rich writing on narrative is abundant with talk on listening to lone voices who whisper into and against the strong wind.

By now you will have caught a glimpse of the preferred facilitator style required to coax out narratives and nurture the 'voice on the edge'. Not surprisingly, they are those qualities associated with all caring and effective relationships: unconditional warmth, genuiness, and non judgemental regard. But of course balanced by the need for judicious challenge when required.

Roth and Fonagy (1996) have noted the amount of research suggesting that it is the qualities of the therapist rather than the actual technique used that result in positive outcomes from therapy. These qualities enable a therapeutic alliance to form, and that seems to be an accurate predictor of change and benefit at the end of therapy. Similarly, I suggest that in order for learners to learn about clinical supervision they should be exposed to facilitators with those qualities that allow them to forge a therapeutic learning alliance. 


\section{Conclusion}

In this paper, I have argued in favour of an oral approach to developing qualified nursing staff to be effective clinical supervisors and clinical supervisees. The use of narrative in clinical supervision training is highly appropriate. Clinical supervisors and clinical supervisees can be prepared to both narrate stories and to encourage narration. It is through the telling of stories that people can revisit and learn from past experience, and become re-connected not only with their past life but life in general. The encouragement of 'story-telling' requires particular facilitator qualities which parallel those associated with helping relationships. This is in contrast to those styles thought to be effective in presenting information; where the all knowing lecturer uses technology to transmit knowledge to the passive consumer.

\section{References}

Clarke, L .2003. Nurse education: why Socrates would disapprove. Nursing Standard, 17 (52) pp 36-37.

Driscoll, J. 2000. Practising Clinical Supervision: A Reflective Approach. London, Bailliere Tindall.

Ghaye, T. 2000. The role of reflection in nurturing creative clinical conversations. In: Ghaye, T. \& Lillyman, S., eds. Effective Clinical Supervision: the role of reflection. Chapter 4, pp55-71, Dinton, Mark Allen.

Hawkins, P., Shohet, R. 2000. Supervision in the Helping Professions an individual, group, and organizational approach. Buckingham, Open University Press.

Johns, C. 2002. Guided Reflection: Reflection in Practice. Oxford, Blackwell Science.

Khanna, R. 2004. Reflective Practice within the occupational therapy curriculum. In: Tate, S. \& Sills, M., eds. The Development of Critical Reflection in the Health Professions: Occasional Paper No.4. Chapter 6, pp 47-53. Higher Education London, Academy Health Sciences and Practice Subject Centre.

Maslach, C. \& Letter, M. 1997. The Truth about Burnout: How organisations cause personal stress and what to do about it. San Francisco, Josey Bass.

McAllister, M. 2001. In harm's way: a postmodern narrative inquiry. Journal of Psychiatric and Mental Health Nursing 8 (5) pp 391 - 397.

McLeod, J. 2002. Lists, Stories, and Dreams: Strategic Invitation to Relationship in Psychotherapy Narrative. In: Strategic Narrative: New Perspectives on the Power of Personal and Cultural Stories (ed. Patterson, W.) Lexington, Oxford.

Musson, G. 1998. 'Life Histories'. In: Symon, G. \& Cassell, C., eds. Qualitative Methods and Analysis in Organizational Research: A Practical Guide. Chapter 2, pp. 10-27. London, Sage.

Nonaka, I. \& Takeuchi, H. 1995. The Knowledge-Creating Company: How Japanese Companies Create the Dynamics of Innovation. Oxford, Oxford University Press.

Roth A. \& Fonagy P. 1996. What works for whom? A critical review of psychotherapy research. New York, Guildford Press.

Schon, D. 1983. . The Reflective Practitioner. New York, Basic Books.

Senge, P. 1994. The Fifth Discipline Fieldbook: Strategies and tools for building a learning organization. London, Nicholas Brearley. 